\title{
The relationship between the mechanism of injury and mandibular fractures
}

SADJ June 2021, Vol. 76 No. 5 p241 - p244

I Abdoola1, MMR Bouckaert², TI Munzhelele ${ }^{3}$, M Ibrahim4, JM Mchenga $^{5}$

\section{ABSTRACT}

\section{Introduction}

This prospective study describes the mechanism of injury, patient demographics and clinical presentation of 100 consecutive patients encountered in the patient population served by the Department of Maxillofacial and Oral Surgery at the Sefako Makgatho Health Sciences University.

\section{Objectives}

To determine the demographics, presentation and mechanism of injury of patients presenting with mandibular fractures in the patient population served by Sefako Makgatho Health Sciences University.

\section{Author affiliations:}

1. Irshaad Abdoola: BChD, MChD (MFOS), FCMFOS, Lenmed Roya Hospital and Heart Center. Previously of Department of Maxillofacial and Oral Surgery, Medunsa Oral Health Centre, Sefako Makgatho Health Sciences University (SMU), Pretoria, South Africa. ORCID Number: 0000-0001-9361-5407

2. Michael MR Bouckaert: MDent, FFD, FCMFOS, Professor, Senio Consultant: Maxillofacial and Oral Surgery, Medunsa Oral Health Centre, Sefako Makgatho Health Sciences University (SMU), Pretoria, South Africa.

ORCID Number: 0000-0001-9337-3671

3. TI Munzhelele: BDS, MDent, Head of Department: Maxillofacia and Oral Surgery, Medunsa Oral Health Centre, Sefako Makgatho Health Sciences University (SMU), Pretoria, South Africa. ORCID Number: 0000-0002-0082-9391

4. Muniera Ibrahim: $B C h D, P D D$ (Sedation and Pain Control) Lenmed Royal Hospital and Heart Center, Kimberley, South Africa. ORCID Number: 0000-0003-2548-4630

5. James M Mchenga: MDent, Bed, $P D D, B D S$, Senior consultant: Maxillofacial and Oral Surgery, Medunsa Oral Health Centre, Sefako Makgatho Health Sciences University (SMU), Pretoria, South Africa.

ORCID Number: 0000-0002-2629-985

Corresponding author: Irshaad Abdoola

Lenmed Royal Hospital and Heart Center. Previously of Department of Maxillofacial and Oral Surgery, Medunsa Oral Health Centre, Sefako Makgatho Health Sciences University (SMU), Pretoria, South Africa.

Suite 106, Lenmed Royal Hospital and Heart Center,

6 Welgevonden Street, Royldene, Kimberley, 8301

Email: maxfax@dr.com

Author contributions:

1. Irshaad Abdoola: Writing article, data collection, data analysis $-60 \%$

2. Michael MR Bouckaert: Corrections - $10 \%$

3. T Irene Munzhelele: Corrections - 10\%

4. Muniera Ibrahim: data analysis, researching relevant related articles - $10 \%$

5. James M Mchenga: Corrections - 10\%

\section{Results}

Seventy percent of mandibular fractures were secondary to assault. Although this was high in comparison to other studies, it was similar to studies performed in London and other regions of South Africa. Mandibular fractures resulting from MVA (motor vehicle accidents), falls and sports were found to be less than the norm.

\section{Conclusion and recommendations}

The high percentage of mandibular fractures due to assault concurs with similar studies previously conducted in South Africa. With some variables similar to international trends, while others are not; certain salient results highlight the need for interventional campaigns.

\section{Keywords}

Mandible, fracture, trauma, maxillofacial, injury, jaw.

\section{INTRODUCTION}

The oldest known literature describing mandibular fractures dates back to the $17^{\text {th }}$ century BC; with the original manuscript believed to have been written during the pyramid age, approximately 3000 BC. ${ }^{1}$ This Ancient Egyptian text proposes no treatment for mandibular fractures. Much knowledge and treatment methods were gained during the years of world wars. ${ }^{2}$ (Hippocrates) said: War is the only proper school for a surgeon. Continued social violence and urban warfare have provided both the need and platform for continued research in the field. The basic principles of traumatology rest on a biologic and anatomic foundation, as was seen by similar fracture patterns by (René Le Fort) in 1901. ${ }^{3}$

\section{DISCUSSION}

With an exception of comminuted condylar head injuries, most $(>75 \%)$ of mandibular fractures occur along areas of primary tensile strain. ${ }^{4}$ Biomechanical analysis has shown a greater tendency of higher fractures, along the condylar head and neck, when the mouth was open at the time of injury; whereas a greater tendency of fractures inferior to the condylar head was noted in injuries sustained with the mouth in a closed position. 5,6 The presence of mandibular third molars increases the risk of mandibular angle fractures. ${ }^{7}$ 
Forces are conducted along buttresses and fractures occur at weak spots. The lowest force required to cause a mandibular fracture is $193 \mathrm{~kg}$, which may fracture a single condyle. $243-250 \mathrm{~kg}$ is needed for bilateral condylar fractures and $386-420 \mathrm{~kg}$ is required for a symphysis fracture.

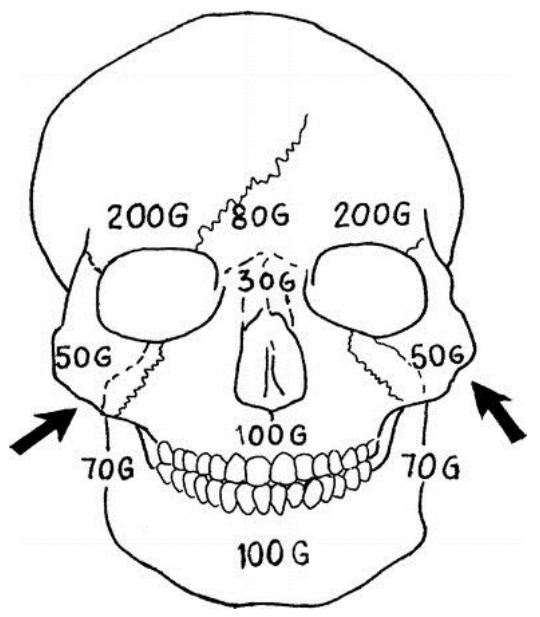

Figure 1. Resistance of force by facial skeleton. ${ }^{8}$

Maxillofacial trauma has been shown to have a wide range of effects, even affecting body posture, which subsequently improves following definitive treatment. ${ }^{9}$ Television is widely accessible and is implicated in violent behavioural modification. ${ }^{10}$ Alcohol consumption is rampant in South Africa and is associated with violence, traffic accidents, crime, considerable morbidity and mortality; with control measures largely being absent. ${ }^{11}$

Studies conducted in Johannesburg demonstrated that $65 \%^{12}$ and $53.8 \%{ }^{13}$ of patients with mandibular fractures had a history of alcohol consumption at the time of injury. Table 1 compares the causes of mandibular fractures of studies from multiple geographic locations, while Table 2 compares the areas of the mandible fractured in these studies.

\section{METHOD}

The study sample included the first 100 consecutive, consenting patients who presented with mandibular fractures; thus being a random patient sample. Patient history, demographics and clinical presentation were recorded. Exclusion criteria included non-consent and inadequate history.

\section{RESULTS}

Patients were mainly of the third to fourth decade (71\%). A male to female ratio of $4.9: 1$ and an unemployment rate of $65 \%$ were noted. The mechanism of injury is summarised in Figure 2. The fracture details and force vectors are summarised in Figure 3, Figure 4 and Table 3.

With $67 \%$ of patients injured between 19:00 and 06:00, an active night life appears to contribute to incidence of mandibular fractures. Although $65 \%$ of the study population reported unemployment, $76 \%$ were alcohol consumers and $55 \%$ inebriated at the time of injury; indicating a potential for unproductive efforts resulting in injurious results.

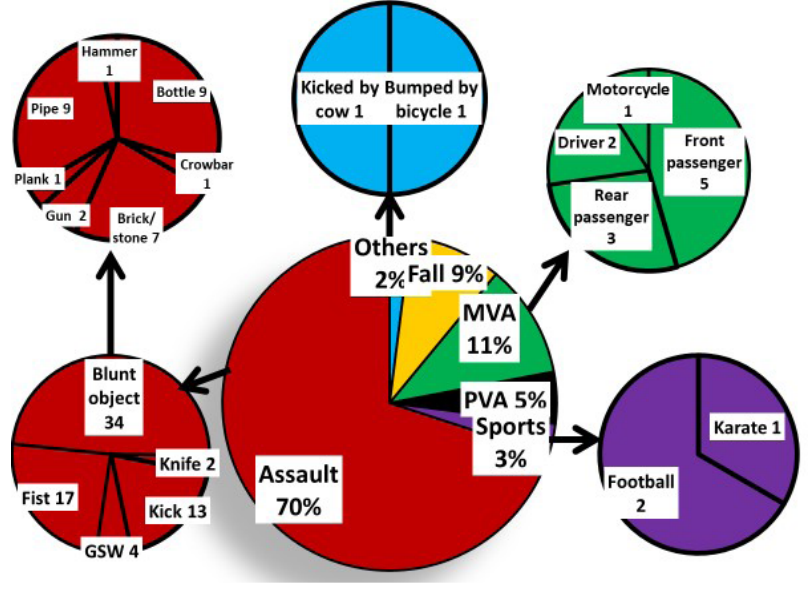

Figure 2. Mechanism of injury.

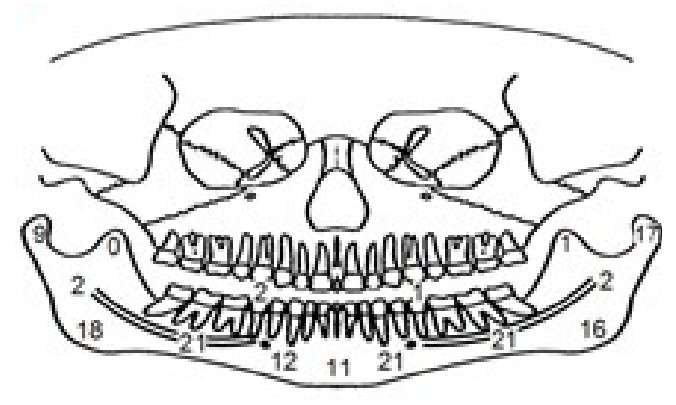

Figure 3. Area of mandible fracture.
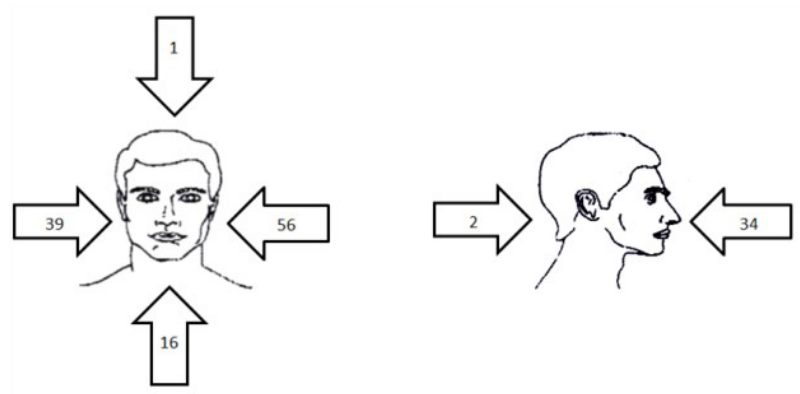

Figure 4. Direction of force sustained.

The percentage $(70 \%)$ of mandibular fractures sustained secondary to assault was found to be high in comparison to other studies. A higher percentage of assaultrelated mandibular fractures were noted in London, ${ }^{19}$ Pretoria $^{25}$ and Ga-Rankuwa ${ }^{23}$ (same patient base as current study, but facial fractures studied).

Mandibular fractures resulting from MVA, falls and sports were found to be less than the national and international norm according to studies referenced.

A higher percentage of mandibular corpus and parasymphyseal fractures were found in relation to studies referenced; while a relatively lower percentage of dentoalveolar fractures were noted, possibly related to a referral bias.

With $58 \%$ of fractures occurring on the left and $88 \%$ of the population being right handed, ${ }^{26}$ the effect of assault 


\begin{tabular}{|c|c|c|c|c|c|c|c|c|c|}
\hline Model & $\%$ Assault & $\%$ MVA & \% Sport & $\%$ Work & $\%$ Fall & $\%$ Other & Total & $\begin{array}{c}\text { Facial/ } \\
\text { Mandibular }\end{array}$ & $\begin{array}{c}\text { Male/ } \\
\text { Female }\end{array}$ \\
\hline \multicolumn{10}{|c|}{ International } \\
\hline Australia $^{14}$ & 29.9 & 28 & 15.4 & 0 & 21.3 & 5.4 & 100 & facial & $4: 1$ \\
\hline Austria $^{15}$ & 12.3 & 11.7 & 31.3 & 5.3 & \multicolumn{2}{|c|}{39.4} & 100 & facial & $2.1: 1$ \\
\hline Bahrain $^{16}$ & 3.1 & 44.6 & 12.3 & 0 & 40 & 0 & 100 & md & $6: 1$ \\
\hline Brazil ${ }^{17}$ & 30.2 & 43.9 & 2.4 & 0 & 19 & 4.5 & 100 & md & $5.5: 1$ \\
\hline China $^{18}$ & 10.1 & 43.6 & 0 & 4.5 & 40 & 1.8 & 100 & md & $2.8: 1$ \\
\hline England $^{19}$ & 72 & 4 & 5 & 0 & 18 & 1 & 100 & md & $6.7: 1$ \\
\hline Pan-Europe ${ }^{20}$ & 39 & 11 & 11 & 3 & 31 & 5 & 100 & facial & $3.6: 1$ \\
\hline \multicolumn{10}{|c|}{ Africa } \\
\hline Benin $^{21}$ & 13.2 & 79.9 & 4.6 & 0.6 & 1.7 & 0 & 100 & md & $4.4: 1$ \\
\hline Nigeria $^{22}$ & 24.5 & 67.5 & 1.3 & 2.6 & 3.5 & 0.6 & 100 & md & $4.3: 1$ \\
\hline Ga-Rankuwa, South Africa ${ }^{23}$ & 80.6 & 15 & 0 & 0 & 4.4 & 0 & 100 & facial & $6.6: 1$ \\
\hline Johannesburg, South Africa ${ }^{24}$ & 54.3 & 26.6 & 0 & 0 & 5.3 & 13.8 & 100 & facial & $4.9: 1$ \\
\hline Pretoria, South Africa ${ }^{25}$ & 72.5 & 14.2 & 1.6 & 0 & 8.8 & 2.9 & 100 & md & $5: 1$ \\
\hline
\end{tabular}

Table 2. Areas of mandible fractured.

\begin{tabular}{|c|c|c|c|c|c|c|c|c|}
\hline$\%$ & Condyle & Coronoid & Ramus & Angle & Corpus & Para symph & Symphysis & Dento-alveolar \\
\hline \multicolumn{9}{|c|}{ International } \\
\hline Australia $^{14}$ & 7.3 & 0 & 16.1 & 25.1 & 30 & \multicolumn{2}{|c|}{21.5} & 0 \\
\hline Austria $^{15}$ & 2.1 & 0 & 8.3 & & 10.4 & & 1.3 & 2.2 \\
\hline Bahrain $^{16}$ & 24.6 & 0 & 0.6 & 39.1 & 20.6 & \multicolumn{2}{|c|}{15.1} & 0 \\
\hline Brazil $^{17}$ & 30 & 1.3 & 2.3 & 15.3 & 24.3 & 16.4 & 8.5 & 0 \\
\hline China $^{18}$ & 36.2 & 0.5 & 2 & 13.3 & 20.7 & \multicolumn{2}{|c|}{23.9} & 3.4 \\
\hline England $^{19}$ & 27 & $<1$ & 3 & 30 & 9 & 27 & 4 & 0 \\
\hline Pan-Europe 20 & 34 & 2 & 3 & 19 & 22 & \multicolumn{2}{|c|}{17} & 3 \\
\hline \multicolumn{9}{|c|}{ Africa } \\
\hline Benin ${ }^{21}$ & 9.8 & 0 & 8.6 & 12.3 & 47.1 & 15.6 & 6.6 & 0 \\
\hline Nigeria $^{22}$ & 10.8 & 0.2 & 1.3 & 24.6 & 29.6 & 21.4 & 7.8 & 4.3 \\
\hline Ga-Rankuwa, South Africa ${ }^{23}$ & 8.5 & 0.8 & 3 & 35.6 & 18.1 & 21.4 & 12.5 & 0 \\
\hline Johannesburg, South Africa ${ }^{24}$ & 16.8 & 0 & 0 & 38.9 & 17.7 & 19.2 & 5.4 & 2 \\
\hline Pretoria, South Africa ${ }^{25}$ & 14.6 & 0.5 & 4.9 & 12.3 & 41.1 & 18.5 & 4.6 & 3.5 \\
\hline
\end{tabular}

by the dominant hand of an assailant appears to have an effect on the mandibular fracture configuration of the study group.

A slightly increased incidence of fracture favourability and markedly decreased incidence of fracture comminution is in accord with the expected lower force encountered in the assaults as opposed to a higher velocity injury (Table 3).

To conclude the discussion on an optimistic note, the trend of cause of injury appears to have changed from a previous report. ${ }^{23}$ Just as the most common cause of mandibular fractures in Baghdad changed over a period of 10 years from assault by fist to shell and bullet injury, ${ }^{27}$ changes in patterns of injury are not uncommon in the same institution at different times. Although (Singh) considered the cause of facial fractures in general, ${ }^{23}$ the current study using the same patient base reveals that assault is no longer as common an injurious cause as in 2009 (a decrease from 80.6\% to $70 \%$ ).

\section{CONCLUSION AND RECOMMENDATIONS}

The correlation between high risk behaviour and social challenges, such as unemployment, violence, excessive alcohol consumption and disregarding the use of seat belts should be considered on an interventional basis.

\section{Table 3. Fracture details.}

\begin{tabular}{|l|c|c|}
\hline & Favourable & Unfavourable \\
\hline Horizontal & 54 & 46 \\
\hline Vertical & 56 & 44 \\
\hline Teeth in fracture line & Yes & No \\
\hline Multi-rooted & 88 & 12 \\
& Yes & No \\
\hline Fracture comminution & 54 & 34 \\
& Yes & No \\
\hline
\end{tabular}

The percentage $(70 \%)$ of patients with mandibular fractures due to assault is indeed a point of concern, which interventional campaigns may target.

Motor vehicle usage patterns, safety features, road conditions and traffic legislature affect the injury patterns associated with MVA. The role of violent sport, occupational risks and other high risk behaviours are other factors that need to be considered when treating the traumatised patient and implementing preventative measures.

A renewed call is made to invest in campaigns reducing these contributing factors to high risk behaviour in light of the effect displayed on the health of the patient population studied. 


\section{Acknowledgments}

Much thanks is due to past and present registrars and dental officers of the department of Maxillofacial and Oral Surgery: Dr C van Niekerk, Dr RS Ciya, Dr IT Dikgale, Dr BR Legalamitloa, Dr KG Leballo.

Ethics

SMUREC ethics reference number: SMUREC/D/8240 05: $P G$.

\section{Conflicts of interest}

The authors declare no conflict of interest.

\section{References}

1. Breasted J. Edwin Smith surgical papyrus. Facsimile and hieroglyphic transliteration with translation and commentary. American Journal of Oral Surgery. 1944; 30: 399-504.

2. Mukerji R, Mukerji G, McGurk M. Mandibular fractures: Historical perspective. Br J Oral Maxillofacial Surg. 2006 Jun; 44(3): 222-8.

3. Gartshore L. A brief account of the life of René Le Fort. $\mathrm{Br}$ J Oral Maxillofacial Surg. 2010 April; 48(3): 173-5.

4. Miloro M. Peterson's principals of oral and maxillofacial surgery. $2^{\text {nd }}$ ed. London: BC Decker; 2004.

5. Petzel J-R, Bülles G. Experimental studies of the fracture behaviour of the mandibular condylar process. J Maxillofac Surg. 1981; 9: 211-5.

6. Santos LS, Rossi AC, Freire AR, Matoso RI, Caria PH, Prado FB. Finite-element analysis of 3 situations of trauma in the human edentulous mandible. J Oral Maxillofac Surg. Apr 2015; 73(4): 683-91.

7. Duan DH, Zhang Y. Does the presence of mandibular third molars increase the risk of angle fracture and simultaneously decrease the risk of condylar fracture? Int J Oral Maxillofac Surg. Jan 2008; 37(1): 25-8.

8. Pappachan B, Alexander M. Biomechanics of cranio-maxillofacial trauma. J Maxillofac Oral Surg. Jun 2012; 11(2): 224-30.

9. Streian F, Argesanu V, Kulcsar RM, Borozan IS, Jula M, Talpos-Niculescu C. Human Body Posture before and after Maxillofacial Surgery. Procedia Engineering. 2014; 69: 508-11.

10. Bryant J, Thompson S, Finklea BW. Fundamentals of Media Effects. $2^{\text {nd }}$ ed. Illinois: Waveland Press. 2013.

11. Bianchi G. Alcohol Use and Sexual Risk Behaviour: A CrossCultural Study in Eight Countries. Geneva: WHO press; 2005.

12. Desai J, Lownie JF, Cleaton-Jones P. Prospective audit of mandibular fractures at the Charlotte Maxeke Johannesburg Academic Hospital. S Afr J Surg. Nov 2010; 48(4): 122-6.

13. Porter M, Lownie M, Cleaton-Jones P. Maxillofacial injury: a retrospective analysis of time lapse between injury and treatment in a South African academic maxillofacial and oral surgery unit. S Afr J Surg. 2013 Oct 22; 51(4): 138-42.

14. Cabalag MS, Wasiak J, Andrew NE, Tang J, Kirby JC, Morgan DJ. Epidemiology and management of maxillofacial fractures in an Australian trauma centre. J Plast Reconstr Aesthet Surg. Feb 2014; 67(2):183-9.

15. Gassner R, Tuli T, Hächl O, Rudisch A, Ulmer H. Craniomaxillofacial trauma: a 10 year review of 9543 cases with 21 067 injuries. J Craniomaxillofac Surg. Feb 2003; 31(1): 51-61.

16. Dhaif G, Ramaraj R, Magra A, Yasser A, Al-Sammak N. Mandibular fractures in Bahrain- A 10 year study. Bahrain Med Bull. Sep 1996; 18(3).

17. Chrcanovic BR, Abreu MH, Freire-Maia B, Souza LN. 1,454 mandibular fractures: a 3-year study in a hospital in Belo Horizonte, Brazil. J Craniomaxillofac Surg. 2012 Feb; 40(2): 116-23.
18. Ongodia D, Zhi Li Z, Hai-Hua Zhou HH, Zu-Bing Li ZB. Comparative analysis of trends in the treatment of mandibular fractures. J Oral Maxfac Surg. July 2014; 26(3): 276-9.

19. Rashid A, Eyeson J, Haider D, van Gijn D, Fan K. Incidence and patterns of mandibular fractures during a 5-year period in a London teaching hospital. Br J Oral Maxillofac Surg. Dec 2013; 51 (8): 794-8.

20. Boffano P, Roccia F, Zavattero E, Dediol E, Uglesic V, Kovacic Z, et al. European Maxillofacial Trauma (EURMAT) project: A multicentre and prospective study. J Craniomaxillofac Surg. Jan 2015; 43(1): 62-70. doi: 10.1016/j.jcms.2014. 10.011. Epub 2014 Oct 22

21. Anyanechi CE \& Saheeb BD. Mandibular sites prone to fracture: analysis of 174 cases in a Nigerian tertiary hospital. Ghana Med J. 2011 Sep; 45(3): 111-4.

22. Adeyemo WL, Iwegbu IO, Bello SA, Okoturo E, Olaitan AA, Ladeinde $A L$, et al. Management of mandibular fractures in a developing country: a review of 314 cases from two urban centers in Nigeria. World J Surg. Dec 2008; 32(12): 2631-5.

23. Singh AS. An audit of maxillofacial fractures in patients attending the Medunsa Oral Health Centre, University of Limpopo, Medunsa Campus. [Updated 2009 June; cited 22 October 2014]. Available from: http://hdl.handle.net/10539/7315.

24. Suleman YF. Aetiology and mechanism of injury of midfacial fractures: a prospective study of the Johannesburg region. [Updated 2008; cited 22 October 2014]. Available from: http:// hdl.handle.net/10539/7350.

Roode GJ, van Wyk PJ, Botha SJ. Mandibular Fractures: an Epidemiological Survey at the Oral and Dental Hospital, Pretoria. SADJ. Jul 2007; 62(6): 270, 272-4.

25. Goodman J. The wages of sinistrality: handedness, brain structure and human capital accumulation. Journal of Economic Perspectives. 2014; 28(4): 193-212.

26. Mahdi AGM, Ali IAA. A retrospective analytic study of mandibular fracture patterns in two different periods in Baghdad. J Oral Maxfac Surg, Med, Path. July 2013; 25(3): 205-9. 